\title{
Prevalence of Seizure Disorder in School Children in Kashmir
}

\author{
Gurmeet Singh ${ }^{1}$, Sheikh M. Saleem², Sheikh Mushtaq Ahmad ${ }^{3}$, Mohammad Ismail ${ }^{4}$ \\ ${ }^{1}$ Consultant, Department of Medicine, District Hospital Baramulla, ${ }^{2}$ Additional Professor, Department of Neurology, Sheri \\ Kashmir Institute of Medical Sciences Soura Srinagar, ${ }^{3}$ Additional Professor, Department of Neonatology, Sheri Kashmir \\ Institute of Medical Sciences, Soura, Srinagar ${ }^{4}$ Lecturer, Department of Medicine, Govt Medical College and Associated \\ Hospitals Srinagar, Jammu and Kashmir, India.
}

Corresponding author: Dr Gurmeet Singh, Consultant Medicine District Hospital Baramulla, Jammu and Kashmir, India.

DOI: http://dx.doi.org/10.21276/ijcmsr.2019.4.1.30

How to cite this article: Gurmeet Singh, Sheikh M. Saleem, Sheikh Mushtaq Ahmad, Mohammad Ismail. Prevalence of seizure disorder in school children in Kashmir. International Journal of Contemporary Medicine Surgery and Radiology. 2019;4(1):A116-A119.

\section{A B S T R A C T}

Introduction: Seizure disorder is highly prevalent disorder particularly in developing countries and there are very less studies conducted in children from underdeveloped and developing countries. The prevalence of the disease is more seen in children of families with low socioeconomic levels. We conducted the study of prevalence of seizure disorder in Kashmir. This study was undertaken to determine the prevalence of seizure disorder of school going children (6-16) years of age. Materials and methods: The study was conducted in six Districts of Kashmir valley (Srinagar, Anantnag, Pulwama, Budgam, Baramulla and Kupwara). The selection of schools was done by PPS (proportionate to population size) used in cluster survey. Questionnaire Performa was given to 60 randomly selected children from each selected school, 30 boys and 30 girls were screened to find out the prevalence of seizure disorder. To give adequate representation to all individuals of various socioeconomic strata. Both Govt and Private run schools from rural as well as urban areas were selected. Those Childrens who fulfilled the requisite criteria for seizure disorder were examined by a Neurologist.

Results: A total of 19 positive cases of seizure disorder were detected during the survey period, After screening of 5760 children (rural and urban) the crude prevalence of epilepsy was found to be 3.3/ 1000 which is comparable to the other studies in the world. The Male prevalence of seizure disorder in school going children was 3.8/1000 while female prevalence of seizure disorder was $2.77 / 1000$. Commonest type of seizure was generalized tonic clonic (GTC) $78.9 \%$. The prevalence of seizure disorder in children of lower socio economic class was 3.5/1000. The Prevalence of seizure order was 3.81/1000 in Govt schools while it was $2.77 / 1000$ in private schools.

Conclusion: The prevalence of seizure disorder is similar to the other studies conducted in developing countries and in India as well. The study also showed an increase in risk for seizure disorder with low socio economic level.

Keywords: Seizure Disorder, School Children

\section{INTRODUCTION}

Seizure disorder is a major health problem in developing countries including southeast Asia. Prevalence of seizure disorder in school going children reported from different countries is 4.4 to 9.9 per 1000 .

The results published till date is discordant because of various methodology, asymmetric protocols and age ranges.

Sidnvall $\mathrm{R}$ et al in Scandinavian study reported prevalence of epilepsy among school children in range of 2.6 to 11.6 per 1000. The aim of our study was to access the prevalence of seizure disorder in school going children from 6 to 16 years. Epilepsy is defined as a condition characterized by recurrent (two or more) epileptic seizures, unprovoked by any immediate identified cause ${ }^{1}$

Epilepsy is a chronic non communicable disease of the brain that effects people of all ages. More that 50 million people worldwide have epilepsy, making it one of the most common neurological disease globally. Nearly $80 \%$ of people with epilepsy live in low and middle- income countries. It is estimated that $70 \%$ of people living with epilepsy could live seizure free if properly diagnosed and treated. About three quarters of people with epilepsy living in low and middle income countries do not get the treatment they need. In many parts of the world, people with epilepsy and their families suffer from stigma and discrimination. ${ }^{2}$

Only one third of the patients with newly diagnosed unprovoked seizures receive an etiological diagnosis. Etiological factors for childhood epilepsy are different from those for epilepsy occurring later in life. ${ }^{3}$ In children, perinatal insults, developmental deficits, genetic factors, degenerative CNS or other malformations and perinatal events (i.e., asphyxia and CNS hemorrhage) are all often identified as possible causes of epilepsy. ${ }^{4}$ This study was undertaken to determine the prevalence of seizure disorder of school going children (6-16) years of age.s

\section{MATERIAL AND METHODS}

The study was conducted in the J\&K state which comprises 
of 3 provinces Jammu Kashmir and Ladakh. The study was conducted in six districts of Kashmir namely Srinagar, Baramulla, Anantnag, Kupwara, Budgam and Kulgam.

Survey population and methods.

Population Chosen was based on Cluster Sampling the study was conducted in Kashmir with total population of 5476970 (male 2877211 females 2519759). The population of school going children was (Males 1231139 females 1101028) census of India 2001. The selection of schools was done by PPS method (proportionate to population size) used in cluster surveys 5

Four steps were used to select the schools to be used in the survey.

Step 1st:- List of schools along with their enrolment was procured from directorate of school education Kashmir Division. The Schools were numbered from 1 to total number of schools with their enrolment (student population cumulative population).

Step 2nd: Sampling interval was calculated by dividing the cumulative by cluster number (30)

Step 3rd: One school which had cumulative population between one and the sampling interval was randomly selected. Sixty students (30 boys and 30 Girls) were screened to find the prevalence of epilepsy.

Step 4th: Next school was selected by adding sampling interval to the cumulative population of the 1st selected school (which was selected in the step 3rd) and so on. 30 children each boys and girls were screened for the epilepsy.

Let total Population $\mathrm{A}+\mathrm{B}+\mathrm{C}+\ldots \ldots=12000$

Interval $=12000 / 30=400$

First selection will be school B, Second school D and so on The study was conducted over a period of two years

\section{Selection of schools using pps method}

\begin{tabular}{|l|l|l|l|}
\hline Schools & $\begin{array}{l}\text { Enrollment } \\
(6-16 \text { Yrs })\end{array}$ & $\begin{array}{l}\text { Cumulative } \\
\text { frequency }\end{array}$ & Cluster \\
\hline A & 200 & 200 & \\
B & 150 & 350 & $230^{\text {th }}$ Individual $~^{\text {st }}$ \\
C & 100 & 450 & \\
D & 250 & 700 & $630^{\text {th }}$ Individual 2 ${ }^{\text {nd }}$ \\
E & 100 & 800 & \\
F & - & - & \\
\hline
\end{tabular}

\begin{tabular}{|l|l|}
\hline Total No of Districts screened in Kashmir Valley & 06 \\
\hline Total No of schools screened in each district & 16 \\
\hline Total No of schools Screened in Valley & 96 \\
\hline No of Govt Schools screened in Kashmir Valley & 48 \\
\hline No of Private Schools Screened in Kashmir Valley & 48 \\
\hline Total no Children screened in each district & 960 \\
\hline Total no Children screened in Kashmir valley & 5760 \\
\hline
\end{tabular}

Before getting permission from the head of school a preformed questionnaire of WHO was administered in local language. Seizures were classified according to ILAE guidelines ${ }^{6}$ with following exclusion criteria.

1. Provoked seizures

2. Febrile Seizures

3. Single Isolated Seizures.
4. Seizures with stroke or trauma

5. Seizures with CNS infections like meningitis encephalitis or brain abscess

6. Pseudo-Seizures, Syncope.

7. Seizures with metabolic and toxic encephalopathy.

On the prefixed day random cluster of 30 boys and 30 girls was taken each children was interviewed in presence of teacher and questionnaire completed further information regarding onset of seizure, place of birth, obstetric history, income, occupation, antenatal history was sort from the parents. Family history of seizure and a visit to Quack/ religious person (PIR) was sort out. From a Methodological prospective difference exists across the studies due to varying sample size, data collection, personal nature of population (Urban/Rural) duration of study, data collection tools, Questionnaire and other factors.

\section{RESULTS}

Out of the total number of screened children for seizure disorder in Kashmir 19 positive cases were confirmed by the neurologist. The crude prevalence of seizure disorder was found to be 3.3/1000 in the study. The prevalence of seizure disorder of all the six districts of Kashmir is represented by Table 1 . The male prevalence of seizure disorder was $3.81 / 1000$ while as female prevalence of seizure disorder was found to be $2.77 / 1000$. The prevalence rate of epilepsy was higher in Government schools $57.9 \%$ as compared to $42.1 \%$ in private schools reflecting higher prevalence in Government School children (table-2). Age specific prevalence was found to be higher in age group (10-12 Years) $52.6 \%$ (table-3). Among the types of seizures GTC was the commonest type $78.9 \%$, followed by partial seizure $10.5 \%$. Absence seizure 5.3\%, unclassified 5.3\% (table-4) gender specific prevalence males had higher prevalence $57.3 \%$ as compared to females (table-5). Social taboos and illiteracy had impact on the seizure disorder. Lowest prevalence of 3.56/1000 was observed in the lower middle class table6.

\section{DISCUSSION}

Epilepsy is second commonest neurological disorder after head ache. The school children are ideal for epidemiological studies, such studies help in policy making as this is social and economic burden on the society. Overall crude prevalence of epilepsy was 3.3/1000.

Kaul R, Razdan S et $\mathrm{al}^{7}$ in stud found of prevalence of epilepsy was $2.47 / 1000$ which is similar to our study.

Sidnavll $\mathrm{R}^{8}$ et al in a Scandinavian study reported prevalence rate of epilepsy among school going children in range of 2.611.6/1000 children. We found Higher prevalence 3.81/1000 in Govt Schools compared to private schools 2.77/1000.

As most Govt Schools are situated in rural areas so the prevalence of epilepsy is higher in rural as compared to urban schools. Aziz $\mathrm{H}^{9}$ et al found higher prevalence of epilepsy in rural areas. A higher prevalence of epilepsy was found in males compared to females reason not known.

Some studies have reported seizure disorder more common in first birth order while others have reported epilepsy in higher birth order.

Based on Kuppuswammy ${ }^{10}$ classification. Higher Prevalence 


\begin{tabular}{|l|c|c|c|c|}
\hline District & Total Population Surveyed & No. of Positive Cases $(\mathbf{n})$ & Prevalence Male & Prevalence female \\
\hline Anantnag & 960 & 3 & 4.16 & 2.08 \\
\hline Pulwama & 960 & 2 & 2.06 & 2.08 \\
\hline Srinagar & 960 & 4 & 4.16 & 4.16 \\
\hline Budgam & 960 & 3 & 4.16 & 2.08 \\
\hline Baramulla & 960 & 3 & 4.16 & 2.08 \\
\hline Kupwara & 960 & 4 & 4.16 & 4.16 \\
\hline Total & 5760 & 19 & 2.81 \\
\hline$X^{2}=0.540, P=0.991(>0.05) N S$ & \multicolumn{5}{|l}{} \\
\hline \multicolumn{4}{|l|}{ Table-1: Demographic Profile } \\
\hline
\end{tabular}

\begin{tabular}{|l|c|c|c|c|}
\hline Type of School & No of Positive Cases (n) & Percentage (\%) & Population at Risk & Prevalence/1000 \\
\hline Government & 11 & $57.9 \%$ & 2880 & 3.81 \\
\hline Private & 08 & $42.1 \%$ & 2880 & 2.77 \\
\hline Total & 19 & & \\
\hline \multicolumn{4}{|r|}{ Table-2: Prevalence of Seizure Disorder in school Going Children according to their schooling status } \\
\hline
\end{tabular}

\begin{tabular}{|l|c|c|c|c|}
\hline Age in Years & No of Positive Cases (N) & Percentage\% & Population at Risk & Prevalence /1000 \\
\hline $6-9$ & 07 & $36.8 \%$ & 1709 & 4.09 \\
\hline $10-12$ & 10 & $52.6 \%$ & 2994 & 3.34 \\
\hline $13-16$ & 2 & $10.5 \%$ & 1057 & 1.89 \\
\hline Total & 19 & & \\
\hline \multicolumn{5}{|l}{} \\
\hline
\end{tabular}

\begin{tabular}{|l|c|c|c|c|c|}
\hline Demographic Variables & $\begin{array}{c}\text { Generalized tonic } \\
\text { clonic (GTC) }\end{array}$ & Partial & Absence & $\begin{array}{c}\text { Unclassified / } \\
\text { mixed }\end{array}$ & Total percentage \\
\hline Districts & $2(66.7 \%)$ & $1(33.3)$ & - & - & $3(15.8)$ \\
\hline Anantnag & $1(50 \%)$ & - & $50 \%$ & - & $2(10.5)$ \\
\hline Pulwama & $4(100 \%)$ & - & - & - & $4(21.0)$ \\
\hline Srinagar & $3(100 \%)$ & - & - & - & $3(15.3)$ \\
\hline Budgam & $2(66.7 \%)$ & $(33.3)$ & - & $1(25 \%)$ & $3(15.8)$ \\
\hline Baramulla & $3(75 \%)$ & - & $1(5.3)$ & $1(5.3)$ & $1(21.0)$ \\
\hline Kupwara & $15(78.9 \%)$ & $2(10.5)$ & - & -19 \\
\hline Total & \multicolumn{7}{|l}{ Table-4: Seizures types (Age group 6-16 years) all the six districts of Kashmir valley } \\
\hline
\end{tabular}

\begin{tabular}{|l|c|c|c|c|}
\hline Sex & No of Positive Cases (N) & Percentage\% & Population at Risk & Prevalence /1000 \\
\hline Males & 11 & $57.9 \%$ & 2880 & 3.81 \\
\hline Females & 8 & $42.1 \%$ & 2880 & 2.77 \\
\hline Total & 19 & & \\
\hline \multicolumn{4}{|l|}{ Table-5: Gender Specific Prevalence rate of epilepsy in school going childrens aged (6-16 years) in Kashmir valley. } \\
\hline
\end{tabular}

\begin{tabular}{|l|c|c|c|c|}
\hline Socio Economics Status & No of Positive Cases (N) & Percentage\% & Population at Risk & Prevalence /1000 \\
\hline Upper Class & 1 & $5.2 \%$ & 306 & 326 \\
\hline Upper Middle Class & 5 & $26.3 \%$ & 1538 & 3.25 \\
\hline Average Middle Class & 6 & $31.57 \%$ & 1791 & 3.35 \\
\hline Lower Middle Class & 4 & $21.0 \%$ & 1123 & 3.56 \\
\hline Lower Class & 3 & $15.7 \%$ & 912 & 3.28 \\
\hline Total & 19 & & \\
\hline \multicolumn{2}{|l|}{ Table-6: Prevalence of epilepsy in school going children in Kashmir valley according to their socioeconomic status } \\
\hline
\end{tabular}

of seizure disorder was found in average middle class. Freeman et $\mathrm{al}^{11}$ found that in children between age group of 7-12 years prevalence was 3.18/1000 population.

Cowan L.D ${ }^{12}$ reported prevalence of Epilepsy in age group of less than 10 years 5-5.3/1000 population, 10-14 years 4.60/1000 population.

Similar were the findings of Koul et al: with prevalence higher in age group of less than 14 years i.e: 3.18/1000 population. 
This is comparable to our study which indicates that prevalence is higher in lower age groups and higher in elderly children.

Classification of Epilepsy was done according to the guidelines of ILAE (international League against Epilepsy). 78.9\% were having GTC in our study

Guvenes at $\mathrm{al}^{13}$ found higher prevalence rates of epilepsy in rural as compared to urban areas. According to Shorvan and Farmer the requirement for EEG in applying the definitions of partial and generalized seizure types the international League Against Epilepsy(ILAE)means that almost no epidemiological studies from the developing countries can truly report seizure type. Hence, there is a chance that so called generalized seizures are in fact secondary generalized. The finding of national general Practice of Epilepsy from the United Kingdom and the study of Waaler PE et al from Norway also approve of it. ${ }^{6,15}$

The present study revealed $52.6 \%$ of the realized shad EEG records available out of which $25 \%$ had normal EEG. Most common Anti Epileptic Drug used was Dyphenyl/hydanton. An economic study from India estimated that public financing for both first and second line therapy and other medical costs elevates the financial burden from epilepsy and is cost effective. ${ }^{14}$

\section{CONCLUSION}

The prevalence of seizure disorder is similar to the other studies conducted in developing countries and in India as well. The study also showed an increase in risk for seizure disorder with low socio economic level.

\section{ACKNOWLEGMENT}

The study as doctorial thesis of Dr Gurmeet Singh and expenditures of the study was born by him only.

\section{REFERENCES}

1. Hauser WA, Annegers JF, Kurland LT. Incidence of epilepsy and unprovoked seizures in Rochester, Minnesota: 1935-1984. Epilepsia 1993;34(3):453-468

2. Epilepsy fact sheet WHO 9 Feb-2016 from original article 2016.

3. Annegers JF. The epidemiology of epilepsy. In: Wyllie E, editor. The treatment of epilepsy. 3rd ed. Philadelphia: Lippincott Williams \& Wilkins; 2001.p. 136-7.

4. (A) Asadi-Pooya AA, Hojabri K. Risk factors for childhood epilepsy: a case control study. Epilepsy Behav 2005;6(2):203-6. (B) Daoud AS, Batieha A, Bashtawi M, El-Shanti H. Risk factors for childhood epilepsy: a case-control study from Irbid, Jordan. Seizure2003;12(3):171-4

5. Kelwin M Sullivan et al. monitoring universal salt iodization programmes ICCIDD (international Council for control cluster Surveys, Chapter 8 p.58.

6. Waller PE, Blom BH, Skeidsvoll H, Mykleteen A. Prevalence, classification and severity of epilepsy in children in western Norway, Epilepsy 2000;41(7) : 802810.

7. Kaul R, Razdan S \& Anil Matta, Prevalence and pattern of epilepsy in rural Kashmir, India Epilepsy 1988;29(2):116-122.
8. Sidenvall R, Forsgren L, Heijbel J. Prevalence and characteristic of Epilepsy in children in North Sweden. Seizure 1996;5(3):139-146.

9. Aziz H, Ali SM, Frances P, Khan MI and Hasan KZ. Epilepsy in Pakistan. A population based epidemiology study. Epilepsia 1994;35(5)950-958.

10. Kupuswamy B Manual of Socioeconomic status scale. Manasyan 32, Netaji Subhash Marg, Delhi 6; 1976.

11. Freeman JM, Jacobi H, Vining E, Carol E Epilepsy in inner city schools- A school based proagramme that makes a difference Epilpsia 1984 ;25(4):438-442.

12. Cowan Linda D, Bodensteiner John B et al. Prevalence of Epilepsy in childrens and adolescents. Epilepsia 1989; 30(1):94-106.

13. Guvenes Aziz H et al ; prevalence of epilepsia in turkey Epilepsia 1989.

14. Mediddo I, Coloson A, Chisholm D, Dua T, nandi A, Laxminarayan R. Health and economic benefits of public financinf of epilepsy treatment in India: An agent-based simulation model. Epilepsy. 2016; 57(3): 464-74.

15. Ross Evan M, Peckham S, Catherine west B Patrick Butts R Neivlle Epilepsy in childhood. Finding from national child development study Br J Med 1988;20710

\section{Source of Support: Nil; Conflict of Interest: None}

Submitted: 01-10-2018; Accepted: 02-11-2018; Published online: 30-03-2019 